\title{
E-LEARNING AND M-LEARNING CONTENT GENERATION AS LEARNING SUPPORT IN ECONOMIC EDUCATION
}

\author{
Mihaela Moca ${ }^{1}$, Alina Badulescu ${ }^{2}$ \\ 1 Doctoral School of Economic Sciences, Faculty of Economic Sciences, University of \\ Oradea, Romania \\ 2 Department of Economics and Business, Faculty of Economic Sciences, University of \\ Oradea, Oradea, Romania \\ moca.mihaela@gmail.com \\ dbadulescu@uoradea.ro
}

\begin{abstract}
The knowledge-based economy and the digital world are steadily transforming the teaching of younger generations but also the role and involvement of the teacher in the educational act. Accepting the essential role of economic education in the development of students' mentalities and abilities, we implicitly recognize the central role played by teachers and teaching methods, as a considerable challenge to transform education, focus on active learning, providing students with new experiences inside and outside the classroom, involving modern methods of learning and experimentation. Generating digital educational content, as well as designing instructional tools that allow easy access to students of this content requires an effort of adaptation by educators for new educational realities. Digital literacy of teachers is necessary, as the first condition, and then it is necessary to form skills that allow the generation of content with characteristics adapted to educational needs, respecting quality criteria and ethical criteria. In this paper, the author also aims to present the ASQ platform as a space where teachers can create digital content, which can be shared nationally with other educators and which can be used successfully in specific economics classrooms.
\end{abstract}

Keywords: e-learning; economic education; ASQ platform; learning content; instructional tool

JEL Classification: A20; 125;D83.

\section{E-learning, m-learning - the new educational reality}

The permanent appeal to education of an individual, can be beneficial for him at any time in his life, taking into account contemporary economic and technological trends, labor market needs, opportunities to adapt, or even succeed, in several professional fields (Csintalan \& Badulescu, 2015). Resuming some of the ideas mentioned in the key acts of EU strategies in the field of growth and education, Csintalan \& Badulescu (2015) insisted that education and skills are elements that increase economic growth; better educational levels are associated with increasing employability of individuals and employment's rate at regional and national level, directly contributing to poverty reduction. Last but not least, we must recognize and promote the idea of an active learning process, based on values of solidarity, equality, inclusion and cooperation (European Commission, 2010), (Csintalan \& Badulescu, 2015). In a survey-based research involving teachers from economic high-schools, Badulescu et al (2020) find that they are fully aware that economic disciplines, financial education and entrepreneurship, provide practical learning opportunities, support students in participating in real situations and extracurricular activities. Finally, a good economic education offers a competitive advantage to the student and additionally arms him/her for life, regardless of the chosen occupation. Moreover, Neck and Greene (2011) argue that education and the teaching of economics must stimulate students to think, and then to act, 
through a diversity of methods. Methods to do this are diverse, some teachers tending to use case studies and simulations; others use texts, official reports and analyses, and others digital application, in order to structure students' availability and ability to process economic and business information.

The technological development of the last decades has made the traditional form of education more and more obsolete, e-learning, m-learning becoming the new kind of education centered on teaching through an innovative and interactive approach. The term e-learning has been defined as being instructions transmitted using electronic devices in order to support learning (Clark and Mayer, 2016).

E-learning differs from traditional education by some very important aspects. First of all, the learner organizes his own training during the working time. The educator, on the other hand, can adapt the pedagogical path of each student, depending on the situation. The activity in e-learning can be continuous, it is not a punctual one, still, having some well-established landmarks in time. The content takes into account individual needs and interactions between participants and the tutor. The contents taught are constantly changing, through the contribution of users, by the experiences along the way of the unique practices used by educators.

Subsequently, the m-learning has emerged as a superior form of e-learning. The term has been introduced by Crompton (2005), in a period of development of global interconnection through World Wide Web (www). The most important aspect that differentiates m-learning from other pedagogical approaches is the possibility for students to carry out learning activities without being tied to a specific fixed location, by using mobile devices to access and communicate information, using wireless technology (Kukulska-Hulme, 2005). This model of distance education, through the use of mobile devices, is very favorable and advantageous to students, who thus have the opportunity to educate regardless of the time and place (Koruku and Alkan, 2011). These teaching methods have become dominant, especially in the current context, when there has been a shift in many education systems to online education.

\section{Generating e-learning and m-learning content and designing the means of transmitting them}

Modern education has to be grounded on promoting a diversity of cognitive approaches, related to a diversity of economic motivations, to take into account a wide range of desired outcomes or definitions of success. Economic education should avoid the idea that results are obtained in a linear and predictable way. Although the use of verified methods can reduce the failure of teaching and learning, many voices argue that this is similar to avoiding innovation and openness to new teaching methods.

Digital education is achieved through forms that differ greatly from traditional communication, being an environment that can generate knowledge, accessibility to new content, interaction for the exchange of ideas, knowledge, the exercise of skills, etc. However, this aspect does not deny the importance of the acquisition by educators, first of all, of the classical tools of human learning and socialization. Cucoș (2020) says that "learning only from the virtual environment, fetishizing it, making this landmark your main way of culturalization, leaving aside what we need until then, is too little, it is simplistic, even dangerous".

The delivery in the virtual environment of some contents, through computer-mediated learning supports, supposes the observance of some standards and quality criteria specific to both virtual learning and traditional education. The digitalization of education has led to the transition from textbooks distributed to students, to new forms of content delivery, which involve the collaboration of the teacher (specialist and pedagogue) with the software creator, 
web designer, possibly psychologist. Another important aspect is related to the compliance of ethics in the generation of these contents or learning supports.

Digital education also involves the development of educators' digital skills. The 21st century digital skills needed by employees in any field are those that ensure the competitive and innovative capacity of organizations (van Larr and van Deursen, 2017). There is a rich literature that addresses the topic of digital competence, introducing several terms that refer to the digital skills needed in the new social and technological environment. Some of these terms are digital skills, digital literacy, or e-skills. Mitrovic (2010) explains e-skills as "the ability to develop and use ICT, to participate in a way as adapted as possible to an environment increasingly dominated by electronically accessed information, as well as the ability to synthesize this information into - an effective and relevant knowledge". One cannot imagine education today without developing these competencies among educators. An official document drafted in 2017 at the level of the European Union, refers strictly to the digital competences of educators, being called "European Framework for the Digital Competences for Educators: DigCompEdu" (Redecker, 2017). The areas of manifestation of digital skills for teachers are presented, which focus on different aspects of their professional activity: the use of digital technologies for communication, collaboration and professional development, attracting, creating and sharing digital resources, teaching and learning through the use of digital technologies, evaluation improved through the use of digital technologies and strategies, etc.

An important aspect to be mentioned when it comes to designing e-learning content, mlearning is that the means used to transmit knowledge is not just a simple way, but is an ingredient of the content, having the role of strengthening the basic idea, to describe and supplement it. On the other hand, it must be understood that the means used to convey the content is no more important than what is actually intended to be transmitted to the learners.

\subsection{Characteristics of e-learning and m-learning contents and tools}

The new curricular approaches in economic education are related to the increased autonomy of the learner, asynchronous teaching-learning and the relocation of training. Starting with these elements, the instructional contents of e-learning, m-learning and their transmission tools must have some important characteristics (Cucoș, 2020) as detailed below.

Thus, the knowledge conveyed must be sequential, the contents must be divided into several independent units, which students gradually go through in order to comprehend the entire content. In this way, students come to understand various complex economic phenomena.

Another important aspect is related to ensuring a global articulation of the content elements, because the economic phenomena and processes are interdependent, each influencing the others. The students' understanding of a phenomenon being related to the approach and understanding of other phenomena, in a coherence specific to the economy.

It is also necessary to individualize the contents according to the particularities of the learners, which will make the topics presented to be differentiated during the training course from one student to another, so that each individual to identify in the proposed material the elements that he is interest in and those he understands.

Ensuring particular rhythms of access and comprehension, which means that it is accepted that not all learners are able to understand everything, not everyone can go through and understand all the instructional content such as e-learning, m-learning and then they should be encouraged to progress at its own pace, recognizing that those contents that have not been fully understood will be addressed and understood in other contents anyway, as the economic phenomena and processes described are interdependent.

The introduction of methodological elements that accompany the knowledge path of learners in courses with economic content involves the use of methodological indicators of understanding, those elements that help learners in identifying new meanings and additional understanding of content, phenomena and economic processes; thus, not only knowledge 
about these elements is transmitted, but learners are challenged to interpret this knowledge in the context of the real economy and to try to understand it, to look for answers and new ways of understanding.

\subsection{Quality criteria in the generation of e-learning and $m$-learning contents and tools}

Adherence to quality criteria in content generation and design of instructional tools such as e-learning, m-learning, achieving a proper design to ensure a positive training experience, must be provided by educators and economic education institutions in a responsible way, with special attention and dedication (Markova et al., 2016). These quality criteria are diverse and refer to aspects related to content, design, aesthetics, level of employment and motivation. Thus, it is very important to have a permanent verification and updating of the contents, so that the information presented is current and relevant. Also, this content must be logical, and the instructional tool must have an attractive and ergonomic design.

The contents and the instructional instrument must allow a certain interactivity, which is achieved by involving the users in their own training, by fulfilling some simple or more complex tasks, conditions in the succession of the educational course. They must also ensure ease of content navigation.

The quality of the contents and instructional tools depends very much on the way in which the educators are motivated to access or use them. For this it is necessary to include several elements of motivational support, such as interesting examples in the form of text or video, place elements, surprise elements or individual research tasks.

The use of multimedia techniques also leads to an increase in the quality of the contents, the use of images, sound and video effects, animations being very useful. This ensures an aesthetic of the instructional content; the users go through the contents without accumulating frustrations and desires to abandon in different phases of it.

Last but not least, a very important qualitative criterion is the adaptability of the contents and instructional tools, they must suit the students to whom they are addressed, to be adequate for them.

\subsection{Respecting ethics in creating e-learning, m-learning contents and learning supports}

Another issue related to the creation and use of e-learning and m-learning content is given by the use of technology in education. The ethic of technology is being analyzed nowadays. The moral norms of mankind were formed and transformed along its evolution from ancient times, still the ethic of technology on the other hand appeared more recently, as computers, tablets, smartphones are relatively recent technological achievements. The first references to the ethics of computer use were made by Norbert Wiener (1950), introducing computer ethics as a branch of philosophy. Moor (1985) says that computer ethics is the analysis of the nature and social impact of computer technology, as well as the formulation and motivation of policies for the ethical use of this technology. Peterson (2017) attempted an adaptation of these ethical principles of technology in education, focusing on the following aspects: the cost-benefit principle, the precautionary principle, the sustainability principle, the autonomy principle, the fairness principle.

The cost-benefit principle says that the use of technology in education is moral only if the net surplus of benefits over costs for students, educators, institutions is relevant. The precautionary principle applies to ensure that all measures are taken to protect learners from any threat. The principle of sustainability stipulates that the use of technology in education is moral only if it does not lead to the depletion of the financial resources of educational institutions through costly investments in technology. The principle of autonomy says that the use of technology in education is moral because the autonomy of both educators and learners is ensured, on the principle of anytime-anywhere. The principle of fairness states 
that the use of technology in education is moral only if it ensures equal access of the learners to resources and teachers, avoiding the inequalities that occur frequently.

When debating the ethical issues related to the digitization process that economic education is undergoing today, there are some important issues. Thus, the problem of plagiarism is very important. It is a phenomenon that manifests itself on the part of both educators and learners. Creating plagiarised content is a serious violation, which is mostly due to the lack of ethics courses in how to produce and publish the content, as well as limited access to quality sources, which are generally not free (Gasparyan et al., 2017).

Another issue is related to "big data", i.e. obtaining consent on how data is collected, data protection, ownership of information. The ethical dilemma is related not only to the degree of consent that students can have regarding the collection and use of this data, but also to the way in which they can access, hold or control their own personal data, i.e. the control of the "digital fingerprint" as well as by correctly assessing the type of data that are considered relevant and useful to support learning and educational decision-making (Facer, 2011).

However, probably the biggest ethical issue is related to evaluation and how the education system will be able to make a correct evaluation through new pedagogical practices, for example online identity management, real or assumed. It also raises the question of how to assess more affective skills or attributes and whether these personal characteristics should be assessed and how the resulting information should be protected (Timmis et al., 2015).

Also, the generation of e-learning content, m-learning involves the collection and analysis of data on learners in order to understand and optimize learning and the environments in which it takes place. However, this learning analytical activity raises problems related to the way in which data about learners are collected and capitalized, most without their acceptance or information, without finding solutions so far to prevent the appearance of unethical behaviour or the appearance of unintended consequences (Willis et al., 2016).

\subsection{Content creation and instructional tool using the ASQ platform}

The aim of this research is to investigate the effectiveness of the use of e-learning content and their use using instructional tools created on an e-learning platform called ASQ.

The ASQ (Another Smart Question) platform is a free educational platform created by a group of enthusiastic Romanian teachers and programmers, who believe that technology can be used creatively in education. This platform is an alternative teaching method, adapted to the current education system, being suitable for all educational disciplines and all years of study. This platform is an example that proves the usefulness of m-learning and highlights the advantages of this learning environment, the application being available on mobile devices to students and teachers, thus ensuring their mobility. The aim of the platform is to offer students learning experiences that are as attractive, dynamic and interactive as possible. It offers the possibility to use different instructional tools, such as lessons with video explanations interspersed with feedback requests, games and competitions between colleagues based on the content already learned, tests and self-assessment functions. For teachers, the major advantage is that an assessment can be made quite efficient by the fact that the platform has tools that allow them to see exactly, at any time, what is the level of knowledge of each student in the class, to identify the shortcomings and to design an individualized route.

\section{Research design}

The analysis that we present here is a quantitative one, based on results obtained from a number of 54 students who worked on the ASQ platform. The control group was composed of 29 students. At the end, a questionnaire was also applied to get feedback from students on the activity. 


\subsection{Data collection tool}

A survey form, consisting of 5 statements, was applied to the experimental group. The purpose was to find out the opinions of the students about the activity on the ASQ platform. Quantitative data were obtained using a Likert-scale with the following options: "Strongly Disagree", "Disagree", "Neither agree nor disagree", "Agree", "Strongly Agree".

\subsection{Study group}

The participants from the experimental group consisted of 54 students from an economical high school, participating at the course of Business Administration. All participants were informed about the nature of the study before the research and participated voluntarily.

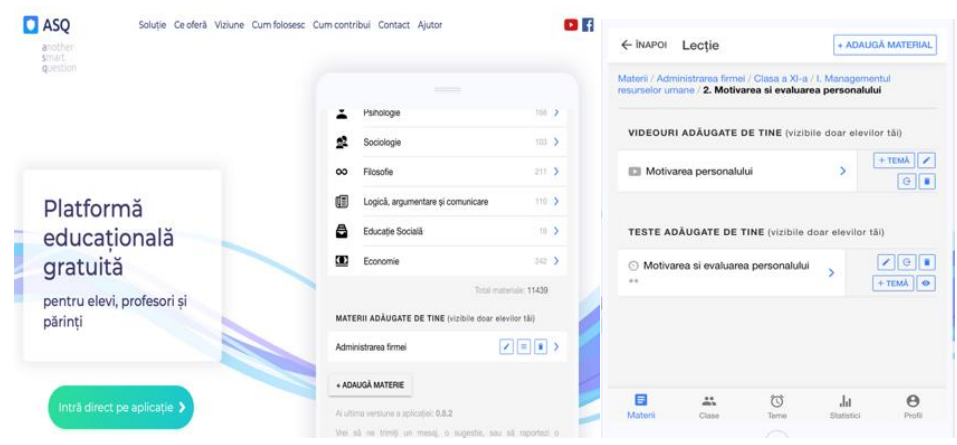

Figure 1. Creating the subject (own archive) Figure 2. Content creation

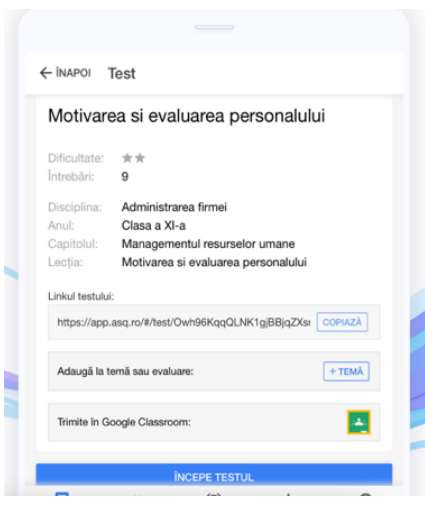

Fig.3. Students survey

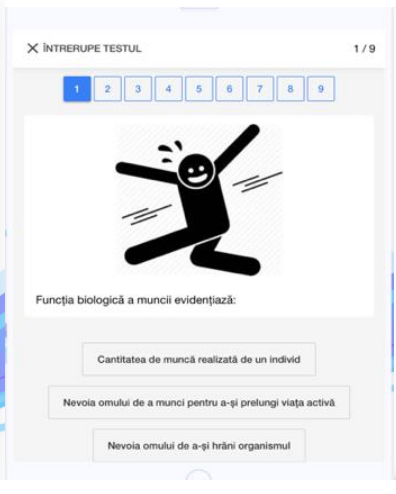

Fig. 4. Test solving

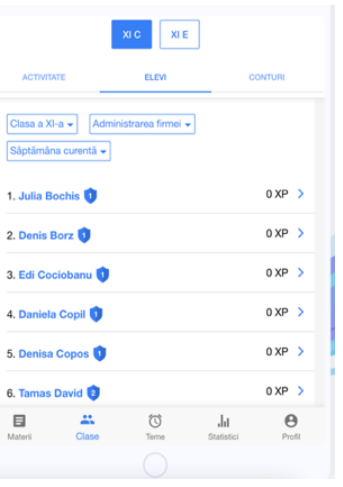

Fig. 5. Results output

We used the ASQ platform, on which instructional content was created, which was then applied in the form of a test to two 11th grade classes, as an instructional tool.

Thus, the discipline of Business Administration was created on the ASQ platform, which is taught in the 11th grade, Technological profile. The discipline created in this way can be accessed only by students registered by the teacher, or be it make be made available to any user of the platform, on the principle of collaborative activities. Two classed were associated with this discipline, with a total of 54 students. They received uploaded materials from the Human Resources Management Content Unit, respectively Personal Rights and Obligations and Personal Motivation and Evaluation. A test was subsequently applied which consisted of 9 questions (each question worth 1 point), the students having subsequent access to feedback, thus making self-assessment possible. 
To compare the results of the two groups, the same test was applied, but in a traditional format to another class. The resulting scores in Table 1.

Table 1. Results for the scores

\begin{tabular}{|r|c|c|c|c|c|c|}
\hline $\begin{array}{r}\text { Type of } \\
\text { evaluation }\end{array}$ & $\begin{array}{r}\text { Number } \\
\text { of } \\
\text { students }\end{array}$ & $\begin{array}{r}\text { Grades } \\
\text { below 5 }\end{array}$ & $\begin{array}{r}\text { Grades } \\
\mathbf{5 - 6 , 9 9}\end{array}$ & $\begin{array}{r}\text { Grades } \\
\mathbf{7 - 8 , 9 9}\end{array}$ & $\begin{array}{r}\text { Grades } \\
\mathbf{9 - 1 0}\end{array}$ & $\begin{array}{r}\text { Average } \\
\text { Score }\end{array}$ \\
\hline $\begin{array}{r}\text { ASQ Test } \\
\mathbf{1}^{\text {st }} \text { class }\end{array}$ & 28 & 1 & 3 & 12 & 12 & 8,10 \\
\hline $\begin{array}{r}\text { ASQ Test } \\
\mathbf{2}^{\text {nd }} \text { class }\end{array}$ & 26 & 1 & 2 & 10 & 13 & 8,42 \\
\hline $\begin{array}{r}\text { Traditional } \\
\text { test }\end{array}$ & 29 & 2 & 4 & 15 & 8 & 7,41 \\
\hline
\end{tabular}

We can conclude that the better results obtained by the experimental group were due to the ways in which the knowledge testing was performed. If, for the experimental group we have used the ASQ platform as testing instrument, in the control group the classical testing was performed. The experimental group was more motivated to answer correctly, more competitive, the evaluation element after each answer contributing to the increase of concentration to generate further correct answers.

\section{Findings}

The results of the survey are as follows:

Q1 "ASQ testing motivates me to respond better"

Students responded in percentage of 26\% Strongly Agree and 31\% Agree, which indicates that students resonate with new assessment methods, which involve technology, being more motivated to solve tasks due to the novelty element.

Q2 "ASQ testing does not cause me anxiety about evaluation"

Students responded in percentage of $42 \%$ Strongly Agree and $28 \%$ Agree, which shows that students do not experience test anxiety being familiar with this online environment, online testing is already used by them in other non-formal, extracurricular contexts.

Q3 "Testing on ASQ seems fun and enjoyable"

Students answered in percentage of $13 \%$ Strongly Disagree, which shows us again that students prefer online activity, using tools they are familiar with and which they prefer to the classic paper test (phone, tablet, etc.).

Q4 "ASQ testing makes me competitive"

Students answered 41\% Strongly Agree and 34\% Agree, which shows that students become more competitive in ASQ testing, due to the display of the score after each question, as well as the results board on the class.

Q5 "ASQ testing makes me involved in solving the test"

Students responded in percentages of 23\% Strongly Agree and 31\% Agree which shows us that students become more involved in ASQ testing, due to the novelty in assessment, their preferences for activities that involve the use of technology.

\section{Conclusions}

In economic education, teaching methods such as e-learning, m-learning have become the normality and not the exception. In that regard, educators must be digitally literate, be able to browse, search and filter data, information and digital content, manage digital content, i.e. organize and store it. Educators must also be able to communicate and collaborate digitally, share content through digital technologies, but most importantly develop digital content and 
integrate digital content into traditional one to create new, original, relevant content. Generating content and learning support such as e-learning, m-learning also involves the design of quality instructional tools through which this content can reach learners. These educational contents must respect certain characteristics and meet quality criteria in order to lead to the achievement of educational objectives together with the instructional tools. An important aspect is the one of ethics in the realization of these contents and in the use of instructional tools, plagiarism being for example a phenomenon that is not yet efficiently stopped.

In economics classrooms, the ASQ platform can be used successfully to generate educational content, being made available to the teacher various instructional tools to transmit knowledge or for assessment. Also, the contents can be shared publicly, with other educators, realizing a collaborative teaching and learning. The results obtained by the students show an increased interest in online ASQ testing compared to the classic one, and in the survey the students showed a positive attitude towards their activity on the platform. However, we mention that more studies are needed on content creation and instructional tools, including on the ASQ platform.

\section{References}

1.Badulescu A., Badulescu D., Csintalan C., Simuț R. (2020), Teaching Entrepreneurship: How Prepared are Romanian Educators?. In: Fotea S., Fotea I., Văduva S. (eds) Challenges and Opportunities to Develop Organizations Through Creativity, Technology and Ethics. GSMAC 2019. Springer Proceedings in Business and Economics. Springer, Cham. https://doi.org/10.1007/978-3030-43449-6 4

2. Clark, R.C., Mayer, R.E (2016) E-lerning and the Science of instruction: Proven Guidelines for Consumers and Designers of Multimedia Learning, John Wilwey\&Sons, NewYork;

3. Crompton, H. (2013), A Historical Overview of M-learning. Toward Learner-Centered Education, "Handbook of Mobile Learning", Vol.29, No.3, pp. 66-75, Berge \& L.Muilenburg, NewYork;

4. Csintalan, C., Badulescu A. (2015) Education and Human Capital as Engines for Economic Growth. A Literature Review, The Annals of the University of Oradea. Economic Sciences, Vol. XXIV, No. 2, pp. $665-673$

5. Cucoș, C. (2020) Generarea conținuturilor școlare/suporturilor de învățare de tipelearning. Caracteristici și criterii de calitate, "Educația digitală", Polirom, Iași, pp. 256;

6. European Commission (2010) Europe 2020. A strategy for smart, sustainable and inclusive growth, Brussels: $\operatorname{COM}(2010) 2020$ final Communication from the Commission.

7. Facer, K. (2011), Learning futures: Education, technology and social change, Abingdon, Oxon, Routledge;

8. Gasparyan, A.Y., Nurmashev, B., Seksenbayev, B., Trukhachev, V.I., Kosyukova, E.I., Kitas, G.D. (2017), Plagiarism in the Context of Education and Evolving Detection Strategies, Journal of Korean Medical Science, Vol.32, No.8, pp.1220-1227;

9. Koruku, A., Alkan, A. (2011), Differences between m-learning (mobile learning) and e-learning, basic terminology and usage of m-learning in education, Procedia Social and Behavioral Sciences;

10. Kukulska-Hulme, A. (2005), Mobile usability and user experience, "Mobile learning: A handbook for educators and trainers", a.kukulska-hulme \& j.traxler (eds) pp. 45-56;

11. Markova, T., Glazkova, I., Zaborova, E., (2016), "Quality Issues of Online Distance Learning", 7th International Conference ob Intercultural Education "Education, Health and ICT for a Transcultural World" EDUHEM2016, Social and Behavioral Sciences, Vol.237, pp. 685-691;

12. Mitrovic, Z. (2010), Positioning e-skills within an organization: An information systems management viewpoint, Journal of Information Management, Vol.12, No.1, pp. 1-7;

13. Moor, J. (1985), What is computer etihics?, Metaphilosophy, Vol.16, No.4, pp. 266-275;

14. Neck, H., Green, P. (2011) Entrepreneurship Education: Known Worlds and New Frontiers. Journal of Small Business Management, Vol. 49, No. 1, pp. 55-70.

15. Peterson, M. (2017), The ethics of technology: A geometric analysis of five moral principles, Oxford University Press; 
16. Redecker, C. (2017), European Framework for the Digital Competence of Educators, JRC Science for Policy Report: DigCompEdu. Punie,Y.(ed);

17. Timmis, S., Broadfoot, P., Sutherland, R., OLdfield, A. (2016), Rethinking assessment in a digital age: opportunities, challenges and risks, British Educational Research Journal, Vol.42, no.3, pp. 454476;

18. van Laar, E., van Deursen, A.J.A.M. (2017), The relation between 21st-century skills and digital skills or literacy: A systematic literature review, Computers in Human Bahavior, no.72, pp. 577-588;

19. Wiener, N. (1950/1989), The Human Use of Human Beings - Cybernetics and Society, Free Association Books/London, First published 1950; 1954, Houghton Mifflin;

20. Willis, J.E., Slade, S., Prinsloo, P. (2012), Ethical oversight of student data in learning analytics: a typology derived from a cross-continental, cross-institutional perspective, Educational Technology Research and Development, Vol.64, pp. 881. 